\title{
Prevalence and Sleep Related Disorders of Restless Leg Syndrome in Hemodialysis Patients
}

\author{
Farzaneh Chavoshi ${ }^{1}$; Behzad Einollahi ${ }^{2}$; Khosro Sadeghniat Haghighi ${ }^{1}$; Maryam Saraei ${ }^{1}$; \\ Neda Izadianmehr ${ }^{3, *}$ \\ ${ }^{1}$ Occupational Sleep Research Center, Baharloo Hospital, Tehran University of Medical Sciences, Tehran, IR Iran \\ ${ }_{2}^{2}$ Nephrology and Urology Research Center, Baqiyatallah University of Medical Sciences, Tehran, IR Iran \\ ${ }^{3}$ Health Research Center, Baqiyatallah University of Medical Sciences, Tehran, IR Iran \\ *Corresponding author: Neda Izadianmehr, Health Research Center, Baqiyatallah University of Medical Sciences, Tehran, IR Iran. Tel:+98-9125856547, E-mail: n.izadian.m@gmail.com
}

Received: October 15, 2014; Revised: November 8, 2014; Accepted: November 15, 2014

\begin{abstract}
Background: Despite being frequently described, Restless Leg Syndrome(RLS) in patients, who are on hemodialysis, is a common disease which, has not been well documented in Iran.

Objectives: The current study aimed to investigate the prevalence of RLS and its sleep disorders in Iranian patients on hemodialysis.

Patients and Methods: In this multicenter cross sectional study, 397 consecutive patients on hemodialysis were evaluated by face-toface interviews. RLS was diagnosed using the International RLS Study Group (IRLSS) criteria. In addition, three validated sleep disorder questionnaires (Insomnia Severity Index, Epworth sleepiness scale and Pittsburgh sleep quality index) were completed by the patients. Results: One hundred-twenty-six patients with RLS (31.7\%; mean age $57.6 \pm 15.4$ years) participated in the current study. RLS mostly occurs in females $(\mathrm{P}<0.001)$. RLS cases showed poorer quality of sleep (Pittsburgh Sleep Quality Index $>5, \mathrm{P}=0.001$ ), higher scores of Epworth Sleepiness Scale $(\mathrm{P}<0.001)$ and insomnia severity index $(\mathrm{P}=0.001)$. Except thyroid gland dysfunction $(\mathrm{P}<0.03, \mathrm{OR} \approx 2.50)$ and antihypertensive medications $(\mathrm{P}<0.01, \mathrm{OR} \approx 1.7)$, there were no significant differences between age, duration of dialysis, etiology of renal insufficiency, intake of nicotine, alcohol or caffeine, and other associated comorbidities between the patients with and without RLS.

Conclusions: In the current study, prevalence of RLS was near the weighted-mean prevalence of other studies (mean 30\%, range 8\%t-52\%). This is not just racial variability and may attribute to narrow or wide definition of the disease, plus variations of the prevalence recording time, and sometimes not using the standard criteria or standard interview.
\end{abstract}

Keywords:Restless Legs Syndrome; Sleep Disorders; Hemodialysis; End Stage Renal Disease (ESRD)

\section{Background}

Restless Legs Syndrome (RLS) is a common and extremely distressing problem experienced by many patients on hemodialysis (HD). It is a neurological condition characterized by an irresistible urge to move legs, especially it occurs during inactivity and at night $(1,2)$.

RLS is described from 1945 in primary and secondary forms; patients with primary RLS are usually younger than 45 and the symptoms progress slowly. It seems that some familial or genetic factors are associated with primary forms of the disease. Secondary RLS occurs in patients with uremia, pregnancy, iron deficiency state, rheumatoid arthritis, diabetes mellitus type 2 and some neuropathies $(3,4)$.

A more important problem is the indescribable symptoms such as pain, itching bones, soda bubbling in veins, worms moving that usually occurs in bed and disturbs the patients and forces them to walk or move the legs to remove this frustrating sensation; therefore, the physi- cians should be more careful about the diagnosis (5).

In addition, the prevalence of RLS in patients who are under treatment with hemodialysis is vary in different studies performed in broad geographical regions (6.6\% - 68\%), and the recent studies using International RLS Study Group criteria (IRLSSG) suggest a prevalence rate of $33 \%$ in patients with the end stage renal disease that is greater than normal population (6). This wide range of differences appears to be related to the character of RLS diagnosis that is clinical and depends on physicians' experience and interview, the RLS validated questionnaire, and the standard criteria are not used in all studies. Moreover, it seems that the different studied populations are important factors $(1,4)$.

Recently some studies showed that HD patients with RLS are more at risk of nocturnal hypertension, heart diseases and perhaps stroke, and the association of other sleep disturbances which could lead to anxiety and depression (7-

Copyright (C) 2015, Nephrology and Urology Research Center. This is an open-access article distributed under the terms of the Creative Commons Attribution-NonCommercial 4.0 International License (http://creativecommons.org/licenses/by-nc/4.0/) which permits copy and redistribute the material just in noncommercial usages, provided the original work is properly cited. 
9). Higher mortality rate in the patients with HD is an important situation that could be an alarm for renal health providers for more medical and supportive care (10).

It is notable that patients with HD have considerably poorer sleep quality than normal population. The presence of RLS and its related sleep disorders could be an added problem and decrease patient's quality of life.

\section{Objectives}

Although, the condition is simply curable and the diagnosis is not expensive uremic RLS is a common, under recognized and not well documented problem in Iran, Thus, the current study aimed to investigate the prevalence and risk factors of RLS in 397 Iranian patients with HD.

\section{Patients and Methods}

\subsection{Patients}

From February to May 2013, 397 consecutive patients with HD from six referral hospitals in Tehran, Iran (Imam Khomeini, Doctor Shariati, Shahid Hasheminejad, Baharloo, Labafi Nejhad, and Baqiyatallah) were enrolled in the study to be evaluated by means of a questionnaire, filled through face-to-face interview.

Demographic information (age, gender, and marital status), Body Mass Index (BMI), medical history, habitual history (alcohol, cigarettes, and coffee), etiology of Chronic Kidney Disease (CKD), and history of kidney transplantation were gathered from their charts.

Co morbid diseases such as: Diabetes Mellitus (DM), anemia (defined by hemoglobin less than $11 \mathrm{mg} / \mathrm{dL}$ for women and $12 \mathrm{mg} / \mathrm{dL}$ for men), neurological, cardiovascular or thyroid gland disease, and dialysis vintage were collected by interviewing and using their charts.

\subsection{Restless Legs Syndrome Diagnosis}

In the current study, RLS was clinically diagnosed by International RLS Study Group criteria (IRLSSG) questionnaire (11). Thus, patients were screened with faceto-face interview considering all four parts of the diagnostic criteria.

\subsection{Assessment of Sleep Disorders}

The patients sleep complaints, insomnia (trouble in falling asleep and/or recurrent awakening with difficulty in falling asleep again and wakeup early in the morning), daytime sleepiness, and sleep quality were assessed with three self-administered validated questionnaires.

Patient with a score above 13 in Insomnia Severity Index (ISI > 13) questionnaire were recognized to have insomnia, daytime sleepiness was assessed with Epworth Sleepiness Scale questionnaire (ESS $>12$ ), and decreased sleep quality was evaluated with the score above eight by Pittsburgh Sleep Quality Index (PSQI > 8) questionnaire (12-14).

\subsection{Statistical Analysis}

Statistical analysis was performed by the SPSS software version16. Categorical variables were expressed as proportions and compared with the chi-square Test variables such as: age and BMI were expressed as means and standard deviations, and were compared with t- tests. $P$-value less than 0.05 were considered statistically significant.

Multivariate logistic regression analysis was used to investigate the association between HD patients' comorbid disease and RLS. Variables of Diabetes mellitus, endocrine gland disorders, anemia, neurologic diseases (neuropathy, Parkinson Disease) and cardiovascular disease were entered listwise into the statistical model to evaluate their contribution. The study was in accordance with Helsinki Declaration and the Ethics Committee of Baqiyatallah University approved the study.

\section{Results}

The study results indicated that out of $397 \mathrm{HD}$ patients 126 (31.7\%) presented RLS (mean age $57.6 \pm 15.4$ years), with higher frequency in females $(47.4 \%$ and $\mathrm{P}<0.001$, $\mathrm{OR} \approx 2.90$ ), there were no significant differences in age, marital status, BMI, smoking, coffee or alcohol consumption, dialysis duration, ethological factors, and history of renal transplantation between the two groups (Table 1 ).

Applying logistic regression analysis among co-morbid disorders, showed that the thyroid gland dysfunction ( $\mathrm{P}$ $<0.03$, OR $\approx 2.01, \mathrm{CI} 95 \% \approx(0.97-4.18))$ was the only condition that differed between the two groups.

The use of drugs did not differ in the two groups except antihypertensive medication $(\mathrm{P}<0.01, \mathrm{OR} \approx 1.7, \mathrm{CI} 95 \% \approx$ (1.12 - 2.68)), related to RLS symptoms (Table 2$)$.

Fifty percent of all the patients were involved with at least one form of sleep disorders. Sleep quality disorder was the most common problem (47.9\%); insomnia and daytime sleepiness were detected in $25.2 \%$ and $24.2 \%$ of patients, respectively.

Sleep disorders were significantly more common in patients with RLS.

Daytime sleepiness was considered in $46 \%$ ( $\mathrm{n}=58$ - $\mathrm{P}<$ $0.001, \mathrm{OR} \approx 8.05, \mathrm{CI} 95 \% \approx(3.2-8.5)$ ) of the patients with RLS; $43.7 \%(\mathrm{n}=55-\mathrm{P}<0.001, \mathrm{OR} \approx 3.89, \mathrm{CI} 95 \% \approx(2.4-6.2))$ had insomnia and $76.2 \%(\mathrm{n}=96-\mathrm{P}<0.001, \mathrm{OR} \approx 6.02, \mathrm{CI}$ $95 \% \approx(3.7-9.7))$ had decreased sleep quality (Table 3 ).

For patients without RLS symptoms, the amounts were $14 \%(n=38), 16.6 \%(n=45)$, and $34.6 \%(n=94)$ for daytime sleepiness, insomnia, and decreased sleep quality, respectively. On the other hand, subgroup analysis identified that diabetes $(P<0.02)$, BMI increase $(P<0.02)$, and age $(\mathrm{P}<0.03)$, could continuously lead to daytime sleepiness. 
Chavoshi F et al.

Table 1. Demographic Characteristics of Hemodialysis Cases According to Presence/Absence of Restless Leg Syndrome ${ }^{a}$

\begin{tabular}{|c|c|c|c|}
\hline Variables & Patients With RLS & Patients Without RLS & $P$-Value \\
\hline Age, mean & 57.6 & 59.8 & 0.47 \\
\hline BMI, $\mathrm{kg} / \mathrm{m}^{2}$ & 24.21 & 24.14 & 0.83 \\
\hline Smoking ${ }^{b}$ & $13(18.8)$ & $56(81.2)$ & 0.45 \\
\hline Coffee, No. & 0 & 2 & 0.45 \\
\hline Alcohol, No. & 0 & 1 & 0.45 \\
\hline History of transplantation ${ }^{b}$ & $12(42.9)$ & $16(57.1)$ & 0.2 \\
\hline \multicolumn{4}{|l|}{ Dialysis sessions } \\
\hline Session per week & 3.10 & 3.08 & 0.41 \\
\hline Time of each session (Hour) & 3.90 & 3.93 & 0.29 \\
\hline Gender $^{\mathrm{b}}$ & & & 0.00 \\
\hline Male & $62(23.7)$ & $200(76.3)$ & \\
\hline Female & $64(47.4)$ & $71(52.7)$ & \\
\hline Marital state ${ }^{b}$ & & & 0.40 \\
\hline Single & $3(2.4)$ & $12(4.4)$ & \\
\hline Married & $123(97.6)$ & $259(95.5)$ & \\
\hline Ethological factor ${ }^{b}$ & & & 0.67 \\
\hline Hypertension & $45(30)$ & $105(70)$ & \\
\hline Diabetes & $50(35.2)$ & $92(64.8)$ & \\
\hline Poly cystic kidney disease & $6(35.3)$ & $11(64.7)$ & \\
\hline Idiopathic & $25(28.4)$ & $63(71.6)$ & \\
\hline
\end{tabular}

${ }^{a}$ Abbreviations: BMI: mass index, RLS: Restless Leg Syndrome.

$\mathrm{b}$ Data is presented as No. (\%).

Table 2. Co-morbidities and Drug History of Hemodialysis Cases According to the Presence/Absence of Restless Leg Syndrome a

\begin{tabular}{|c|c|c|c|c|c|}
\hline Variables & $\begin{array}{c}\text { Patients With } \\
\text { RLS, No. (\%) }\end{array}$ & $\begin{array}{l}\text { Patients Without } \\
\text { RLS, No. (\%) }\end{array}$ & OR Crude (CI 95) & Adjusted OR & P-Value \\
\hline \multicolumn{6}{|l|}{ Co-morbidities } \\
\hline Diabetes & $58(36.5)$ & $101(63.5)$ & $1.43(0.93-2.20)$ & $0.714(0.45-1.12)$ & 0.14 \\
\hline Endocrine Gland disorders & $17(53.1)$ & $15(49.9)$ & $2.01(0.97-4.18)$ & $0.434(0.19-0.96)$ & 0.03 \\
\hline Anemia & $16(27.6)$ & $42(72.4)$ & $0.79(0.42-1.47)$ & $0.917(0.46-1.83)$ & 0.80 \\
\hline Neurologic disease (neuropathy, PD) & $5(18.5)$ & $22(81.5)$ & $0.46(0.17-1.26)$ & $1.622(0.56-4.65)$ & 0.36 \\
\hline Cardiovascular disease & $26(27.1)$ & $70(72.9)$ & $0.74(0.44-1.24)$ & $1.088(0.62-1.88)$ & 0.76 \\
\hline \multicolumn{6}{|l|}{ Drug history } \\
\hline Anti - hypertensive & $81(37)$ & $138(63)$ & $1.73(1.12-2.68)$ & & 0.01 \\
\hline Diabetic modifier & 59 (33.9) & $115(66.1)$ & $1.19(0.78-1.82)$ & & 0.44 \\
\hline Corticosteroid & $15(36.6)$ & $26(63.4)$ & $1.27(0.64-2.49)$ & & 0.48 \\
\hline Lipid profile modulator & $68(33)$ & $138(67)$ & $1.13(0.4-1.72)$ & & 0.59 \\
\hline
\end{tabular}

a Abbreviations: RLS: Restless Leg Syndrome.

Table 3. Sleep Disorders of the Subjects on Hemodialysis According to Presence/Absence of Restless Leg Syndrome ${ }^{\text {a }}$

\begin{tabular}{lcccc}
\hline Variables & $\begin{array}{c}\text { Patients With } \\
\text { RLS, No. }(\%)\end{array}$ & $\begin{array}{c}\text { Patients Without } \\
\text { RLS, No. (\%) }\end{array}$ & P-value & OR(CI 95) \\
\hline Day time sleepiness $($ ESS $<\mathbf{1 2})$ & $58(46)$ & $38(14)$ & 0.001 & $5.2(3.2-8.5)$ \\
Insomnia $($ ISI $<$ 13) & $55(43.7)$ & $45(16.6)$ & 0.001 & $3.89(2.4-6.2)$ \\
Decreased sleep quality $($ PSQI $>$ 8) & $96(76.2)$ & $94(34.6)$ & 0.001 & $6.02(3.7-9.7)$ \\
\hline
\end{tabular}

a Abbreviations: ESS: Epworth Sleepiness Scale, ISI: Insomnia Severity Index, PSQI: Pittsburgh Sleep Quality Index, RLS: Restless Leg Syndrome. 


\section{Discussion}

In the present study, the prevalence of RLS was about $31.7 \%$, which was similar to those of the recent studies (6, $15)$, although some others reported different rate such as: $21.5 \%$ in Brazil (16), 14\% in Canada (17), 18.4\% - 21.5\% in Italy (18), 6.6\% in India (19), 20.3\% in Syria (20), and 62\% in China (21). This high variability may be due to the differences between the number of studied subjects, using different methods, or RLS diagnostic criteria in these studies; and not just because of racial, or geographical differences.

RLS was more frequent in females, which is supported by the fact that RLS can occur during pregnancy and it may relate to the highest levels of estrogen, or psychological changes; the current study results were similar to the explanations of several other studies on female gender as a risk factor for RLS $(16,22)$.

No statistical differences were observed between the two groups regarding caffeine, alcohol, or cigarette use, like that of Salman study; it could be related to some national behavior, or faking (20).

Moreover, antihypertensive drug consumption was related to RLS. According to some studies, hypertension can be a risk factor for RLS, and despite different reports, further studies are needed to investigate the role of hypertension or antihypertensive drugs (23). In the current study among co-morbidities, anemia did not correlate with the presence of RLS symptoms, like some other studies $(2,9,17,21)$.

Lack of this relation is not far-fetched. Whereas, the conditions such as gastric bypass surgery, frequent blood donation, elderly, CKD, and pregnancy that increase risk of Iron Deficiency Anemia (IDA) also increase the risk of RLS, but the role of anemia or iron deficiency are not well defined, yet (24).

It should be mentioned that marginal levels of brain iron, intracellular iron dysfunction, and central role of it in brain dopamine metabolism, are defined as etiological causes by many studies $(9,25-27)$.

Some studies confirmed the relationship between iron deficiency and RLS, even in the absence of anemia (28), however, the peripheral blood hemoglobin and ferritin are not good predictors to evaluate brain iron status $(17,29)$.

In the current study, thyroid disorders were the only co-morbid disease correlated with the presence of RLS symptoms. Other studies presented that the Thyroid Stimulating Hormone (TSH) had a circadian releasing rhythm that rose at nightfall, and the times that the severity of RLS symptoms were presented. On the other hand, Dopamine Agonists (DA), as the main treatments used for RLS relief, have a depressive effect on the thyroid axis too. Some studies demonstrated that treating hypothyroid patient with L-thyroxin could develop signs and symptoms of RLS, and they confirmed that elevated thyroid hormones are provocative conditions for RLS-like symptoms (24, 30-33).

As for the effect of several drugs that are inducers of CYP 450 activity to improve the symptoms of RLS, it seems that further studies are needed to investigate the relationship and effects of thyroid hormones, and the related iron enzymatic interactions with uremic RLS. In the current study, patients who had RLS symptoms experienced more sleep disorders than the others, similar to the results obtained by Gigli et al. (8).

Sleep quality disorder was the most common sleep problem among these patients. RLS could be an etiological factor, or just attendant with other sleep disorders; insomnia and reduction of sleep quality could lead to daytime sleepiness and mood disorders. Other studies suggested that HD patient with RLS also had other sleep disorders such as: daytime sleepiness, insomnia, and poor sleep quality which were directly related to their quality of life and mortality rate (10). Sleep fragmentation and sleep deprivation caused by RLS may contribute to the cardiovascular complications and infections, often with bad prognosis in patients on hemodialysis. Limitations of the current study were Parity and Kt/V index, which were not included.

The high prevalence of RLS and other sleep disorders among uremic patients requires careful investigation of nocturnal sleep, although often under diagnosed; correct identification of these disorders can lead to better therapy and improvement of clinical conditions and quality of life. The most important diagnostic factor for a physician is to mention that a third of HD patients with such conditions.

\section{Acknowledgements}

The collaboration of Dr. Ali Kabir (Shahid Beheshti University of Medical Sciences) for his useful comments is highly appreciated.

\section{Funding/Support}

The study was funded by Health Research Center of Baqiatallah University of Medical Sciences, Tehran, Iran.

\section{References}

1. Kavanagh D, Siddiqui S, Geddes CC. Restless legs syndrome in patients on dialysis. Am J Kidney Dis. 2004;43(5):763-71.

2. Molnar MZ, Novak M, Szeifert L, Ambrus C, Keszei A, Koczy A, et al Restless legs syndrome, insomnia, and quality of life after renal transplantation. J Psychosom Res. 2007;63(6):591-7.

3. Ekbom KA. Restless legs syndrome. Acta Med Scand.1945;158(122)

4. Allen RP. Controversies and challenges in defining the etiology and pathophysiology of restless legs syndrome. Am J Med. 2007;120(1 Suppl 1):S13-21.

5. Allen RP, Picchietti D, Hening WA, Trenkwalder C, Walters AS, Montplaisi J, et al. Restless legs syndrome: diagnostic criteria, special considerations, and epidemiology. A report from the restless legs syndrome diagnosis and epidemiology workshop at the National Institutes of Health. Sleep Med. 2003;4(2):101-19.

6. Kathy P, Mark U. ERSD patient handout,patient guide to EndStage Renal Disease (ESRD) and RLS. NightWalkers. 2008;Summer:21-2.

7. Unruh ML, Sanders MH, Redline S, Piraino BM, Umans JG, Chami $\mathrm{H}$, et al. Subjective and objective sleep quality in patients on 
conventional thrice-weekly hemodialysis: comparison with matched controls from the sleep heart health study. Am J Kidney Dis. 2008;52(2):305-13.

8. Gigli GL, Adorati M, Dolso P, Piani A, Valente M, Brotini S, et al. Restless legs syndrome in end-stage renal disease. Sleep Med. 2004;5(3):309-15.

9. Einollahi B, Izadianmehr N. Restless Leg Syndrome: A Neglected Diagnosis. Nephro Urol Mon. 2014;6(5)

10. Walters AS. . Co-morbidity, morbidity and mortality in the restless legs syndrome. 2nd WASM World Congress. 4-8 February Bangkok. Sleep Med: 2007. pp.11-47.

11. Walters AS, LeBrocq C, Dhar A, Hening W, Rosen R, Allen RP, et al. Validation of the International Restless Legs Syndrome Study Group rating scale for restless legs syndrome. Sleep Med. 2003;4(2):121-32.

12. Johns MW. Reliability and factor analysis of the Epworth Sleepiness Scale. Sleep.1992;15(4):376-81.

13. Hashmi AM, Khawaja IS, Butt Z, Umair M, Naqvi SH, Jawad Ul H. The Pittsburgh Sleep Quality Index: validation of the Urdu translation.J Coll Physicians Surg Pak. 2014;24(2):123-6.

14. Johns MW. A new method for measuring daytime sleepiness: the Epworth sleepiness scale. Sleep.1991;14(6):540-5.

15. Kutner NG, Zhang R, Bliwise DL. Restless legs syndrome is underdiagnosed in the US Renal Data System. QJM. 2013;106(5):487.

16. Araujo SM, de Bruin VM, Nepomuceno LA, Maximo ML, Daher Ede F, Correia Ferrer DP, et al. Restless legs syndrome in end-stage renal disease: Clinical characteristics and associated comorbidities. Sleep Med. 2010;11(8):785-90.

17. Mucsi I, Molnar MZ, Ambrus C, Szeifert L, Kovacs AZ, Zoller R, et al. Restless legs syndrome, insomnia and quality of life in patients on maintenance dialysis. Nephrol Dial Transplant. 2005;20(3):571-7.

18. Merlino G, Piani A, Dolso P, Adorati M, Cancelli I, Valente M, et al Sleep disorders in patients with end-stage renal disease undergoing dialysis therapy. Nephrol Dial Transplant. 2006;21(1):184-90.

19. Bhowmik D, Bhatia M, Gupta S, Agarwal SK, Tiwari SC, Dash SC. Restless legs syndrome in hemodialysis patients in India: a case controlled study. Sleep Med. 2003;4(2):143-6.

20. Salman SM. Restless legs syndrome in patients on hemodialysis. Saudi J Kidney Dis Transpl. 2011;22(2):368-72.
21. Hui DS, Wong TY, Ko FW, Li TS, Choy DK, Wong KK, et al. Prevalence of sleep disturbances in chinese patients with end-stage renal failure on continuous ambulatory peritoneal dialysis. Am J Kidney Dis. 2000;36(4):783-8.

22. Berger K, Luedemann J, Trenkwalder C, John U, Kessler C. Sex and the risk of restless legs syndrome in the general population. Arch Intern Med. 2004;164(2):196-202.

23. Batool-Anwar S, Malhotra A, Forman J, Winkelman J, Li Y, Gao X. Restless legs syndrome and hypertension in middle-aged women. Hypertension. 2011;58(5):791-6.

24. Patrick LR. Restless legs syndrome: pathophysiology and the role of iron and folate. Altern Med Rev. 2007;12(2):101-12.

25. Allen R. Dopamine and iron in the pathophysiology of restless legs syndrome (RLS). Sleep Med. 2004;5(4):385-91.

26. Connor JR, Ponnuru P, Wang XS, Patton SM, Allen RP, Earley CJ. Profile of altered brain iron acquisition in restless legs syndrome. Brain. 2011;134(Pt 4):959-68.

27. Connor JR, Wang XS, Patton SM, Menzies SL, Troncoso JC, Earley CJ, et al. Decreased transferrin receptor expression by neuromelanin cells in restless legs syndrome. Neurology. 2004;62(9):1563-7.

28. Sloand JA, Shelly MA, Feigin A, Bernstein P, Monk RD. A doubleblind, placebo-controlled trial of intravenous iron dextran therapy in patients with ESRD and restless legs syndrome. Am J Kidney Dis. 2004;43(4):663-70.

29. Allen RP, Earley CJ. The role of iron in restless legs syndrome. Mov Disord. 2007;22 Suppl 18:S440-8.

30. Tan EK, Ho SC, Koh L, Pavanni R. An urge to move with L-thyroxine: clinical, biochemical, and polysomnographic correlation. Mov Disord. 2004;19(11):1365-7.

31. Tan EK, Ho SC, Eng P, Loh LM, Koh L, Lum SY, et al. Restless legs symptoms in thyroid disorders. Parkinsonism Relat Disord. 2004;10(3):149-51.

32. Pereira JJ, Pradella-Hallinan M, Lins Pessoa H. Imbalance between thyroid hormones and the dopaminergic system might be central to the pathophysiology of restless legs syndrome: a hypothesis. Clinics (Sao Paulo). 2010;65(5):548-54.

33. Cervenka S, Palhagen SE, Comley RA, Panagiotidis G, Cselenyi Z, Matthews JC, et al. Support for dopaminergic hypoactivity in restless legs syndrome: a PET study on D2-receptor binding. Brain. 2006;129(Pt 8):2017-28. 